\title{
Disturbance of systemic antioxidant profile in nonsmall cell lung carcinoma
}

\author{
J.C. Ho*, M. Chan-Yeung*, S.P. Ho*, J.C. Mak*, M.S. Ip*, G.C. Ooi" ${ }^{\#}$, M.P. Wong", \\ K.W. Tsang* and W.K. Lam*
}

ABSTRACT: The present study aimed to determine the alterations of antioxidant activities in erythrocytes from patients with nonsmall cell lung carcinoma (NSCLC).

A comparative study of the systemic antioxidant activities in red blood cell lysate from subjects with NSCLC and healthy control subjects was conducted. The antioxidants catalase, superoxide dismutase (SOD) and glutathione peroxidase (GPx) were measured using chemical kinetic reactions under spectrophotometry.

In total, 189 cases of mostly advanced-stage IIIB or stage IV NSCLC and 202 healthy controls were studied. In subjects with lung cancer, there was similar catalase activity, lower SOD activity (median (interquartile range) 13.4 (9.0-27.2) versus 48.7 (27.0-64.3) U.(ghaemoglobulin( $\left.(\mathrm{Hb})^{-1}\right)$, and higher GPx activity (175.2 (126.6-288.3) versus $\left.49.2(39.5-59.2) \mathrm{mU} \cdot(\mathrm{gHb})^{-1}\right)$ compared with controls. The antioxidant activities in lung cancer subjects were not associated with age, sex, smoking status, or tumour cell types. However, more advanced disease (stage IV compared with stage IIIB) was associated with lower SOD activity. Using multivariable analysis, the presence of lung cancer independently predicted SOD and GPX activities.

In conclusion, nonsmall cell lung carcinoma in Chinese subjects is associated with alterations in systemic antioxidant activities, which may play an important role in carcinogenesis.

\section{KEYWORDS: Catalase, glutathione peroxidase, lung cancer, superoxide dismutase}

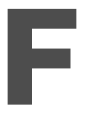
ree radicals and reactive oxygen species (ROS), in particular the superoxide anion and hydroxyl radical, have been implicated in the pathogenesis of various diseases including cancer development [1]. The interaction between superoxide and nitric oxide can produce potentially harmful and powerful oxidants, including peroxynitrite [2]. Human lungs are particularly vulnerable to the potential damage by ROS because of their constant exposure to environmental oxygen and exogenous free radicals, e.g. in cigarette smoke or air pollutants. In order to protect against the deleterious effects of ROS, a well-developed antioxidant system exists in the lung, which includes superoxide dismutases (SODs), catalase, and glutathione-dependent enzymes like glutathione peroxidase (GPx) [3]. SOD enzymes include the intracellular manganese $(\mathrm{Mn})$ SOD and copper-zinc ( $\mathrm{CuZn}$ ) SOD, and an extracellular SOD that exists in epithelial lining fluid and blood vessels [4]. SOD converts superoxide anions to hydrogen peroxide and catalase converts hydrogen peroxide to water and oxygen [5]. GPx also helps in the detoxification of hydrogen peroxide and lipid peroxides, requiring glutathione and other cofactors. A previous study has shown that ingestion of food rich in antioxidants was associated with a decreased incidence of lung cancer [6]. However, the landmark primary prevention trials using vitamins $\mathrm{A}$ and $\mathrm{E}$ have not been able to demonstrate their beneficial effect on lung cancer prevention [7,8]. Therefore, a better understanding of the exact role and alteration of antioxidant profiles in lung cancer is essential to enable the future therapeutic use of antioxidants in the management of lung cancer.

A recent study has identified decreased catalase and increased Mn SOD expressions in resected nonsmall cell lung carcinoma (NSCLC) [9]. However, there has been limited data on the systemic antioxidant profiles in lung cancer, which are represented mostly by the antioxidants in erythrocytes and plasma. In a previous study of 36 nonpulmonary malignant solid tumours, catalase activity in erythrocytes was significantly elevated, suggesting an adaptive response to oxidative stress [10]. Since lung carcinomas, like other types of solid tumours, are characterised by a rich supply of circulating blood, the current authors postulated that antioxidant activities in the systemic compartment, as reflected by those in erythrocytes, would be altered in the presence of lung tumours. Therefore, a comparative study
AFFILIATIONS

University Depts of *Medicine,

${ }^{*}$ Diagnostic Radiology, and

"Pathology, The University of Hong

Kong, Queen Mary Hospital,

Hong Kong SAR, China.

CORRESPONDENCE

J.C. $\mathrm{Ho}$

Division of Respiratory and Critical

Care Medicine

University Dept of Medicine

The University of Hong Kong

Queen Mary Hospital

Pokfulam

Hong Kong SAR

China

Fax: 85228555411

E-mail: jcmho@netvigator.com

Received:

January 012006

Accepted after revision:

September 142006

SUPPORT STATEMENT

This study is partially funded by the University Department of Medicine Research Grant 2002, the University of Hong Kong, Hong Kong SAR, China.

STATEMENT OF INTEREST

None declared. 
on the systemic antioxidant activities was conducted in patients with confirmed NSCLC.

\section{MATERIALS AND METHODS Subject recruitment}

Consecutive subjects with histologically or cytologically confirmed diagnosis of NSCLC were recruited before the initiation of any anti-cancer therapy in the Queen Mary Hospital (Hong Kong SAR, China), a tertiary University-based referral centre for lung cancer, from July 1999 to December 2001. The revised lung cancer staging system was adopted as defined elsewhere [11]. The healthy controls were recruited as part of a population-based lung-function study of nonsmokers and smokers conducted by eight hospitals in Hong Kong. Briefly, individuals $>18$ yrs old were recruited by telephone using random digit dialling. Only subjects with no history of lung cancer or other chest diseases were recruited as controls. There was no matching of age or sex between lung cancer patients and healthy subjects. Trained research assistants interviewed patients and controls using a questionnaire to obtain demographic data and information about smoking habits, presence or absence of chest symptoms and past history of chest diseases and surgery. An ever-smoker was defined as someone who had smoked at least one cigarette (or pipe, water pipe, cigar or hand-rolled cigarette) a day for $\geqslant 1 \mathrm{yr}$. Informed consent was obtained from all patients and controls taking part in the study. All patients and controls were of Chinese origin. The study was approved by the Institutional Review Board of the University of Hong Kong.

\section{Blood collection}

Venous blood $(10 \mathrm{~mL})$ in lithium heparin was taken from each lung cancer patient and control. Red blood cells were separated from plasma and buffy coat by immediate centrifugation at $1,600 \times g$ for $10 \mathrm{~min}$ and stored at $-70^{\circ} \mathrm{C}$ for subsequent assays of antioxidant activities. Red blood cell lysate was prepared by washing packed red blood cells three times with cold normal saline under centrifugation at $3000 \times g$, cells were then lysed with four volumes of cold deionised water. Haemoglobin $(\mathrm{Hb})$ concentrations were assayed by a commercially available kit (Sigma, St. Louis, MO, USA).

\section{Antioxidant activities}

\section{Catalase}

The quantification of catalase activity in the red cell lysate was based on the reaction with hydrogen peroxide as previously described [12]. Briefly, the initial rate of disappearance of hydrogen peroxide (0-60 s) was recorded spectrophotometrically at a wavelength of $240 \mathrm{~nm}$. One unit of catalase activity was defined as the rate constant of the first-order reaction. The catalase activity was expressed as milliunits $(\mathrm{mU}) \cdot(\mathrm{gHb})^{-1}$.

\section{SOD}

SOD activity in the red cell lysate was determined from the rate of reduction of cytochrome c [4], with one unit of SOD activity defined as the amount of SOD required to inhibit the rate of cytochrome c reduction by $50 \%$. The final reaction volume was $3 \mathrm{~mL}$, and included $50 \mathrm{mM}$ potassium phosphate buffer, $2 \mathrm{mM}$ cytochrome c, $0.05 \mathrm{mM}$ xanthine, and a $0.1 \mathrm{mM}$ ethylenediamine tetra-acetic acid (EDTA) solution. Xanthine oxidase (Sigma) was added at a concentration sufficient to induce a 0.020 change in absorbance $\cdot \mathrm{min}^{-1}$ at $550 \mathrm{~nm}$. The SOD activity was expressed as $\mathrm{U} \cdot(\mathrm{gHb})^{-1}$.

\section{Glutathione peroxidase}

Total GPx activity was determined spectrophotometrically in the red cell lysate via an indirect coupled assay [13]. The reactions were carried out using the Bioxytech GPx-340 assay kit (Oxis, Portland, OR, USA). The red cell lysate was added to the proprietary assay buffer and reagent consisting of glutathione, glutathione reductase and reduced $\beta$-nicotinamide-adenine dinucleotide phosphate (NADPH). The reaction was initiated by the addition of $350 \mu \mathrm{L}$ of $0.007 \%$ tert-butyl hydroperoxide. The decrease in absorbance at $340 \mathrm{~nm}$ over $3 \mathrm{~min}$, as NADPH is converted to nicotinamide adenine dinucleotide phosphate, was proportional to the GPx activity. One unit of activity was defined as the activity that catalyses the oxidation of $1 \mathrm{nmol} \mathrm{NADPH} \cdot \mathrm{min}^{-1}$, with a molar extinction coefficient of $6.22 \times 10^{6} \cdot \mathrm{M}^{-1} \cdot \mathrm{cm}^{-1}$ used for NADPH. The GPx activity was expressed as $\mathrm{mU} \cdot(\mathrm{gHb})^{-1}$.

\section{Statistics}

The basic demographic data were expressed as mean $\pm \mathrm{SD}$, and the specific antioxidant activities in median and interquartile range (IQR). Where appropriate, independent sample unpaired t-tests and Chi-squared tests were used to compare the demographic data between cases and controls. The comparison of specific antioxidant activities between cases and controls was achieved using general linear model multivariable analysis, taking confounding variables into account. Pearson correlation analysis was used for testing relationships between different antioxidants among cases. A nonparametric Mann-Whitney U-test was used to compare the specific antioxidant activities between groups with different clinical characteristics. A p-value $<0.05$ was taken to be of statistical significance.

\section{RESULTS}

\section{Clinical characteristics}

There were 189 patients with NSCLC and 202 healthy controls recruited in this study; all were Chinese (table 1). The lung cancer cases were significantly older and had more eversmokers than controls, but with similar sex distribution. The predominant type of NSCLC was adenocarcinoma $(55.6 \%)$, with the majority $(90 \%)$ in stage IIIB or IV of the disease.

\section{Antioxidant activities in NSCLC cases}

In NSCLC cases, there were no correlations between erythrocyte catalase, SOD and GPx activities. There were significantly lower median (IQR) SOD (13.4 (9.0-27.2) versus 48.7 (27.064.3) $\left.\mathrm{U} \cdot(\mathrm{gHb})^{-1}\right)$ and higher median GPx (175.2 (126.6-288.3) versus $\left.49.2(39.5-59.2) \mathrm{mU} \cdot(\mathrm{gHb})^{-1}\right)$ activities in erythrocytes of NSCLC cases compared with controls (table 2). However, the erythrocyte catalase activities were not significantly different between NSCLC cases and controls. Using general linear model multivarible analysis, the presence of lung cancer was an independent predictor of erythrocyte SOD and GPx activities but age, sex and smoking status were not.

In ever-smokers, there were significantly lower median (IQR) SOD (16.5 (8.8-31.6) versus $\left.48.8(21.9-70.7) \mathrm{U} \cdot(\mathrm{gHb})^{-1}\right)$ and higher GPx (166.7 (103.6-275.1) versus 46.5 (38.7-58.6) $\left.\mathrm{mU} \cdot(\mathrm{gHb})^{-1}\right)$, but similar catalase $(7.6(4.5-16.2)$ versus 26.4 


\begin{tabular}{|c|c|c|c|c|}
\hline \multirow[t]{2}{*}{ TABLE 1} & \multicolumn{4}{|c|}{$\begin{array}{l}\text { Clinical characteristics and demographics of } \\
\text { nonsmall cell lung cancer (NSCLC) patients and } \\
\text { control subjects }\end{array}$} \\
\hline & & Controls & NSCLC & $p$-value \\
\hline \multicolumn{2}{|l|}{ Subjects $\mathbf{n}$} & 202 & 189 & \\
\hline \multicolumn{2}{|l|}{ Age yrs } & $49.5 \pm 15.6$ & $57.0 \pm 11.7$ & $<0.001$ \\
\hline \multicolumn{2}{|l|}{ Males } & $119(59)$ & $126(67)$ & $>0.05$ \\
\hline \multicolumn{5}{|c|}{ Smoking status } \\
\hline \multicolumn{2}{|l|}{ Ever-smoker } & $78(39)$ & $105(56)$ & \\
\hline \multicolumn{2}{|l|}{ Nonsmoker } & $124(61)$ & $84(44)$ & 0.026 \\
\hline \multicolumn{5}{|c|}{ Tumour cell types } \\
\hline \multicolumn{2}{|c|}{ Adenocarcinoma } & & $105(55.6)$ & \\
\hline \multicolumn{2}{|c|}{ Squamous cell } & & $32(16.9)$ & \\
\hline \multicolumn{2}{|l|}{ Large cell } & & $16(8.5)$ & \\
\hline \multicolumn{2}{|c|}{ Unclassified NSCLC } & & $36(19.0)$ & \\
\hline \multicolumn{5}{|c|}{ Overall TNM stage } \\
\hline \multicolumn{2}{|l|}{$|-| \mid$} & & $5(2.6)$ & \\
\hline \multicolumn{2}{|l|}{ IIIA } & & $8(4.2)$ & \\
\hline \multicolumn{2}{|l|}{ IIIB } & & $61(32.3)$ & \\
\hline \multicolumn{2}{|l|}{ IV } & & $109(57.7)$ & \\
\hline \multicolumn{2}{|l|}{ Unknown } & & $6(3.2)$ & \\
\hline
\end{tabular}

Data are presented as mean $\pm \mathrm{SD}$ or $\mathrm{n}(\%)$. TNM: tumour, node, metastasis.

(17.2-34.3) $\left.\mathrm{mU} \cdot(\mathrm{gHb})^{-1}\right)$ activities in erythrocytes of NSCLC cases compared with controls (table 3). Similarly, in nonsmokers, the erythrocyte catalase (8.0 (4.2-14.2) versus 19.0 $\left.(14.0-27.7) \mathrm{mU} \cdot(\mathrm{gHb})^{-1}\right)$ activity was similar, while SOD $(12.6$ (9.2-23.5) versus $\left.48.7 \quad(30.1-62.3) \quad \mathrm{U} \cdot(\mathrm{gHb})^{-1}\right)$ activity was significantly lower, but GPx (189.9 (142.7-335.0) versus 50.9 $\left.(39.7-60.0) \mathrm{mU} \cdot(\mathrm{gHb})^{-1}\right)$ activity was significantly higher in NSCLC cases compared with controls (table 3).

\section{Clinical predictors of antioxidant activities in NSCLC cases}

There were no differences in antioxidant activities (catalase, SOD and GPx) in NSCLC cases with respect to age, sex,

\begin{tabular}{cccc} 
TABLE 2 & $\begin{array}{l}\text { Antioxidant activities in red blood cell lysate in } \\
\text { nonsmall cell lung cancer (NSCLC) patients and } \\
\text { control subjects }\end{array}$ \\
& Controls & NSCLC & p-value ${ }^{\#}$ \\
\hline $\begin{array}{c}\text { Catalase } \\
\mathrm{mU} \cdot(\mathrm{gHb})^{-1}\end{array}$ & $20.9(15.4-31.1)$ & $7.6(4.5-15.5)$ & 0.68 \\
$\mathrm{n}$ & 202 & 189 & \\
$\mathbf{S O D}$ & & $13.4(9.0-27.2)$ & $<0.001$ \\
$\mathrm{U} \cdot(\mathrm{gHb})^{-1}$ & $48.7(27.0-64.3)$ & 186 & \\
$\mathrm{n}$ & 202 & $175.2(126.6-288.3)$ & $<0.001$ \\
$\mathbf{G P x}$ & $49.2(39.5-59.2)$ & 186 & \\
$\mathrm{mU} \cdot(\mathrm{gHb})^{-1}$ & 181 & & \\
$\mathrm{n}$ & & &
\end{tabular}

Data are presented as median (interquartile range), unless otherwise stated. Hb: haemoglobin; SOD: superoxide dismutase; GPx: glutathione peroxidase.

${ }^{\#}$ Adjusted for age, sex and smoking status.

\begin{tabular}{|c|c|c|c|c|}
\hline \multirow[t]{2}{*}{ TABLE 3} & \multicolumn{4}{|c|}{$\begin{array}{l}\text { Antioxidant activities in red blood cell lysate in } \\
\text { nonsmall cell lung cancer (NSCLC) patients and } \\
\text { control subjects according to smoking status }\end{array}$} \\
\hline & $\begin{array}{l}\text { Smoking } \\
\text { status }\end{array}$ & Controls & NSCLC & p-value ${ }^{\#}$ \\
\hline \multicolumn{5}{|l|}{ Catalase } \\
\hline $\mathrm{mU} \cdot(\mathrm{gHb})^{-1}$ & ES & $26.4(17.2-34.3)$ & $7.6(4.5-16.2)$ & 0.45 \\
\hline$n$ & & 78 & 105 & \\
\hline \multicolumn{5}{|l|}{ SOD } \\
\hline$U \cdot(g H b)^{-1}$ & ES & $48.8(21.9-70.7)$ & $16.5(8.8-31.6)$ & $<0.001$ \\
\hline$n$ & & 78 & 104 & \\
\hline \multicolumn{5}{|l|}{ GPx } \\
\hline $\mathrm{mU} \cdot(\mathrm{gHb})^{-1}$ & ES & $46.5(38.7-58.6)$ & $166.7(103.6-275.1)$ & $<0.001$ \\
\hline $\mathrm{n}$ & & 74 & 105 & \\
\hline \multicolumn{5}{|l|}{ Catalase } \\
\hline $\mathrm{mU} \cdot(\mathrm{gHb})^{-1}$ & NS & $19.0(14.0-27.7)$ & $8.0(4.2-14.2)$ & 0.90 \\
\hline$n$ & & 124 & 84 & \\
\hline SOD & & & & $<0.001$ \\
\hline$U \cdot(g H b)^{-1}$ & NS & $48.7(30.1-62.3)$ & $12.6(9.2-23.5)$ & \\
\hline $\mathrm{n}$ & & 124 & 82 & \\
\hline \multicolumn{5}{|l|}{ GPx } \\
\hline $\mathrm{mU} \cdot(\mathrm{gHb})^{-1}$ & NS & $50.9(39.7-60.0)$ & $189.9(142.7-335.0)$ & $<0.001$ \\
\hline$n$ & & 107 & 81 & \\
\hline
\end{tabular}

Data are presented as median (interquartile range), unless otherwise stated. $\mathrm{Hb}$ : haemoglobin; SOD: superoxide dismutase; GPx: glutathione peroxidase ES: ever-smokers; NS: nonsmokers. ${ }^{\#}$ Adjusted for age and sex.

smoking status and tumour cell types (table 4). However, more advanced tumour staging was associated with lower median (IQR) SOD activities in erythrocytes (12.2 (8.2-25.0) versus 17.0 (9.4-44.0) $\mathrm{U} \cdot(\mathrm{gHb})^{-1}$ in stage IV and stage IIIB, respectively). There was a trend for GPx activity to be higher in those with stage IV disease.

\section{DISCUSSION}

The present study has demonstrated increased GPx, but decreased SOD activities in erythrocytes in patients with NSCLC compared with healthy controls. This alteration in systemic antioxidant profile was independent of age, sex and smoking status. The presence of clinically evident metastatic (stage IV) disease was associated with significantly lower erythrocyte SOD activity and a trend for higher GPx activity compared with locally advanced (stage IIIB) disease.

Previous studies have suggested a general trend of decrease in various antioxidants (selenium [14], vitamins A and E [15], SOD [16], GPx [14] and glutathione S-transferase [14]) in blood obtained from lung cancer patients compared with controls. In a recent case-control study, erythrocyte CuZn SOD and catalase activities were significantly increased in subjects with NSCLC compared with healthy controls, while GPx activity was only numerically higher in NSCLC subjects [17]. However, the apparently discrepant results from the present study could be related to lack of measurement of Mn SOD and ethnic differences in functional polymorphisms of antioxidant genes $[18,19]$. Surgical removal of lung cancer resulted in augmentation of total plasma radical-trapping antioxidant parameters 
TABLE 4 Effects of clinical characteristics on antioxidant activities in red blood cell lysate in nonsmall cell lung cancer patients

\begin{tabular}{|c|c|c|c|c|c|c|c|}
\hline Characteristics & $\mathrm{n}$ & Catalase $\mathrm{mU} \cdot(\mathrm{gHb})^{-1}$ & $\mathrm{p}$-value & SOD $U \cdot(g H b)^{-1}$ & $p$-value & GPx mU $(g \mathrm{gHb})^{-1}$ & $p$-value \\
\hline \multicolumn{8}{|l|}{ Age yrs } \\
\hline$\geqslant 57$ & 98 & $7.7(4.4-16.4)$ & & $19.0(8.4-32.6)$ & & $172.5(104.8-268.4)$ & \\
\hline$<57$ & 91 & $7.4(4.7-14.9)$ & 0.85 & $12.0(9.2-20.4)$ & 0.10 & $186.6(136.8-330.5)$ & 0.14 \\
\hline \multicolumn{8}{|l|}{ Sex } \\
\hline M & 126 & $7.8(4.5-22.6)$ & & $14.8(9.0-26.8)$ & & $167.2(109.0-276.4)$ & \\
\hline $\mathrm{F}$ & 63 & $7.3(3.9-13.4)$ & 0.32 & $12.7(8.7-30.2)$ & 0.59 & $178.2(138.4-330.2)$ & 0.21 \\
\hline \multicolumn{8}{|l|}{ Smoking status } \\
\hline ES & 105 & $7.6(4.5-16.2)$ & & $16.5(8.8-31.6)$ & & $166.7(103.6-275.1)$ & \\
\hline NS & 84 & $8.0(4.2-14.2)$ & 0.66 & $12.6(9.2-23.5)$ & 0.16 & $189.9(142.7-335.0)$ & 0.06 \\
\hline \multicolumn{8}{|c|}{ Tumour cell types } \\
\hline$A D$ & 105 & $7.3(4.3-13.4)$ & & $12.7(8.7-32.7)$ & & $175.2(130.0-320.7)$ & \\
\hline Non-AD & 84 & $8.2(4.5-17.6)$ & 0.25 & $15.4(9.3-24.7)$ & 0.59 & $179.6(116.0-268.5)$ & 0.50 \\
\hline \multicolumn{8}{|c|}{ Overall TNM stage } \\
\hline IIIB & 61 & $7.7(4.7-14.5)$ & & $17.0(9.4-44.0)$ & & $180.2(129.9-280.7)$ & \\
\hline IV & 109 & $6.9(4.2-15.1)$ & 0.46 & $12.2(8.2-25.0)$ & 0.03 & $189.9(121.3-313.8)$ & 0.63 \\
\hline
\end{tabular}

Data are presented as median (interquartile range), unless otherwise stated. Hb: haemoglobin; SOD: superoxide dismutase; GPx: glutathione peroxidase; M: male; F: female; ES: ever-smokers; NS: nonsmokers; AD: adenocarcinoma; TNM: tumour, node, metastasis.

due to unidentified antioxidant components and protein sulphydryl groups, which reflected the relief of oxidative stress caused by the malignant tumours [20]. It been suggested that chronic inflammation contributes to lung carcinogenesis [21], and inflammatory cell infiltration appeared abundantly in the direct vicinity of resected lung tumours [22]. The extent of inflammation was also found to significantly affect the antioxidant status in lung cancer, with negative correlations between C-reactive protein and retinol, $\alpha$-tocopherol, and lutein [23]. Recently, a study of the antioxidant status in resected NSCLC and adjacent tumour-free lung tissues suggested altered expressions of major antioxidants in tumour tissues [9]. Specifically, there were upregulated Mn SOD and downregulated catalase activities, protein and RNA expressions in lung tumour tissues. The in vivo results were also reproduced by cytokine stimulation in A549 cells. Therefore, more efficient conversion of superoxide into hydrogen peroxide, together with decreased removal of the latter, would result in accumulation of hydrogen peroxide within the tumour cells. Hydrogen peroxide has been implicated in causing genetic damage [24], while superoxide mediates apoptosis [25, 26]. The high levels of Mn SOD with decreased catalase may create an anti-apoptotic intracellular environment which is especially susceptible to increased frequency of mutations, a situation likely to lead to cell transformation and cancer.

The finding of increased erythrocyte GPx activity in patients with NSCLC in the current study suggests an enhanced removal of hydrogen peroxide in the peripheral blood compartment, which may help in counteracting the increased accumulation of hydrogen peroxide within lung tumours. It has been suggested that hydrogen peroxide has a stimulatory effect on SOD activity [27]. Therefore, with the enhanced removal of hydrogen peroxide in erythrocytes, there will be less accumulation of hydrogen peroxide leading to the diminished erythrocyte SOD activity. With this postulate of the systemic antioxidant profile serving as a compensatory mechanism in the presence of lung tumours, the more advanced disease with larger tumour bulk may be associated with greater alteration in the systemic antioxidant profile, accounting for the significantly lower erythrocyte SOD activity in stage IV compared with stage IIIB disease.

Cigarette smoking, the most important cause of lung cancer, has been shown to be associated with depletion of some plasma antioxidants including vitamin $C, \alpha$-tocopherol, carotenoids, glutathione-S-transferase and GPx [28, 29]. This negative effect of cigarette smoking on plasma micronutrients was not limited to active smokers; serum carotenoids were also found to be reduced in passive smokers [30]. Smoking cessation was also shown to restore the initially reduced plasma vitamins A, C, E, uric acid, total thiols and carotenoids [31]. However, some of these effects might be related to the differences in diet between smokers and nonsmokers. Having adjusted for dietary antioxidant intake, recent studies have consistently demonstrated depletion of ascorbic acid, but not other antioxidants, in plasma from smokers [32, 33]. Interestingly, smoking a single cigarette has been demonstrated to significantly and acutely lower the concentrations of major serum antioxidants (ascorbic acid, cysteine, methionine and uric acid) [34]. In addition, an age-dependent adaptive response to antioxidants has been suggested, leading to significant reduction of plasma GPx activity only in older smokers, who could no longer sustain a counteracting effect to oxidative stress [35]. In the present cohort of NSCLC cases, smoking status was not found to be a predictor of activity of these three antioxidants, this may be the result of interplay of the factors above and possibly the effect of the presence of lung tumours.

The findings in the present study are limited by the clinical characteristics of the patient cohort which consisted predominantly of those with adenocarcinoma and advanced disease. 
That adenocarcinoma is becoming the predominant cell type in lung cancer has been recognised in Hong Kong and elsewhere since the early 1990s [36, 37]. A larger study with the inclusion of more nonadenocarcinoma cell types and early-stage diseases may help to better delineate the role of pathologic cell types and disease stages in systemic antioxidant profiles. Future study is warranted to investigate the clinical significance of systemic antioxidant activities as markers of disease status.

\section{ACKNOWLEDGEMENTS}

The authors would like to thank K. Chow and C. Yan for their help in data and sample collection, and C. Ko for his statistical advice.

\section{REFERENCES}

1 Cerutti PA. Prooxidant states and tumor promotion. Science 1985; 227: 375-381.

2 Patel RP, Levonen A, Crawford JH, Darley-Usmar VM. Mechanisms of the pro- and anti-oxidant actions of nitric oxide in atherosclerosis. Cardiovasc Res 2000; 47: 465-474.

3 Seidman MD, Quirk WS, Shirwany NA. Reactive oxygen metabolites, antioxidants and head and neck cancer. Head Neck 1999; 21: 467-479.

4 Erzurum SC, Danel C, Gillissen A, Chu CS, Trapnell BC, Crystal RG. In vivo antioxidant gene expression in human airway epithelium of normal individuals exposed to $100 \%$ O2. J Appl Physiol 1993; 75: 1256-1262.

5 Putnam CD, Arvai AS, Bourne Y, Tainer JA. Active and inhibited human catalase structures: ligand and NADPH binding and catalytic mechanism. J Mol Biol 2000; 296: 295-309.

6 Brennan P, Fortes C, Butler J, et al. A multicenter casecontrol study of diet and lung cancer among non-smokers. Cancer Causes Control 2000; 11: 49-58.

7 The effect of vitamin $\mathrm{E}$ and beta carotene on the incidence of lung cancer and other cancers in male smokers. The Alpha-Tocopherol, Beta Carotene Cancer Prevention Study Group. N Engl J Med 1994; 330: 1029-1035.

8 Omenn GS, Goodman GE, Thornquist MD, et al. Risk factors for lung cancer and for intervention effects in CARET, the Beta-Carotene and Retinol Efficacy Trial. J Natl Cancer Inst 1996; 88: 1550-1559.

9 Ho JC, Zheng S, Comhair SA, Farver C, Erzurum SC. Differential expression of manganese superoxide dismutase and catalase in lung cancer. Cancer Res 2001; 61: 8578-8585.

10 Hristozov D, Gadjeva V, Vlaykova T, Dimitrov G. Evaluation of oxidative stress in patients with cancer. Arch Physiol Biochem 2001; 109: 331-336.

11 Greene FL, Page DL, Fleming ID, et al., eds. American Joint Committee on Cancer Staging Manual. 6th Edn. New York, Springer, 2002.

12 Aebi H. Catalase in vitro. Methods Enzymol 1984; 105: 121-126.

13 Paglia DE, Valentine WN. Studies on the quantitative and qualitative characterization of erythrocyte glutathione peroxidase. J Lab Clin Med 1967; 70: 158-169.

14 Gromadzinska J, Wasowicz W, Rdyzynski K, SzeszeniaDabrowska N. Oxidative-stress markers in blood of lung cancer patients occupationally exposed to carcinogens. Biol Trace Elem Res 2003; 91: 203-215.

15 Kumagai Y, Pi JB, Lee S, et al. Serum antioxidant vitamins and risk of lung and stomach cancers in Shenyang, China. Cancer Lett 1998; 129: 145-149.

16 Martin-Mateo MC, Molpeceres LM, Ramos G. Assay for erythrocyte superoxide dismutase activity in patients with lung cancer and effects on pollution and smoke trace elements. Biol Trace Elem Res 1997; 60: 215-226.

17 Kaynar H, Meral M, Turhan H, Keles M, Celik G, Akcay F. Glutathione peroxidase, glutathione-S-transferase, catalase, xanthine oxidase, $\mathrm{Cu}-\mathrm{Zn}$ superoxide dismutase activities, total glutathione, nitric oxide, and malondialdehyde levels in erythrocytes of patients with small cell and non-small cell lung cancer. Cancer Lett 2005; 227: 133-139.

18 Shimoda-Matsubayashi $S$, Matsumine $H$, Kobayashi $T$, Nakagawa-Hattori Y, Shimizu Y, Mizuno Y. Structural dimorphism in the mitochondrial targeting sequence in the human manganese superoxide dismutase gene. A predictive evidence for conformational change to influence mitochondrial transport and a study of allelic association in Parkinson's disease. Biochem Biophys Res Commun 1996; 226: 561-565.

19 Forsberg L, Lyrenas L, de Faire U, Morgenstern R. A common functional C-T substitution polymorphism in the promoter region of the human catalase gene influences transcription factor binding, reporter gene transcription and is correlated to blood catalase levels. Free Radic Biol Med 2001; 30: 500-505.

20 Erhola M, Nieminen MM, Kellokumpu-Lehtinen P, et al. Effects of surgical removal of lung cancer on total plasma antioxidant capacity in lung cancer patients. J Exp Clin Cancer Res 1998; 17: 219-225.

21 Ballaz S, Mulshine JL. The potential contributions of chronic inflammation to lung carcinogenesis. Clin Lung Cancer 2003; 5: 46-62.

22 Parafiniuk M, Czerwinski F, Parafiniuk W. Vascular changes and inflammatory infiltrations in primary lung cancers. Patol Pol 1989; 40: 293-309.

23 Talwar D, Ha TK, Scott HR, et al. Effect of inflammation on measures of antioxidant status in patients with non-small cell lung cancer. Am J Clin Nutr 1997; 66: 1283-1285.

24 Islam KN, Kayanoki Y, Kaneto H, et al. TGF- $\beta 1$ triggers oxidative modifications and enhances apoptosis in HIT cells through accumulation of reactive oxygen species by suppression of catalase and glutathione peroxidase. Free Radic Biol Med 1997; 22: 1007-1017.

25 Hirose K, Longo DL, Oppenheim JJ, Matsushima K. Overexpression of mitochondrial manganese superoxide dismutase promotes the survival of tumor cells exposed to interleukin-1, tumor necrosis factor, selected anticancer drugs, and ionizing radiation. FASEB J 1993; 7: 361-368.

26 Kuninaka S, Ichinose Y, Koja K, Toh Y. Suppression of manganese superoxide dismutase augments sensitivity to radiation, hyperthermia and doxorubicin in colon cancer cell lines by inducing apoptosis. Br J Cancer 2000; 83: 928-934.

27 Kosenko EA, Kaminsky YuG, , Stavrovskaya IG, Sirota TV, Kondrashova MN. The stimulatory effect of negative air ions and hydrogen peroxide on the activity of superoxide dismutase. FEBS Lett 1997; 410: 309-312. 
28 Liu CS, Chen HW, Lii CK, Tsai CS, Kuo CL, Wei YH. Alterations of plasma antioxidants and mitochondrial DNA mutation in hair follicles of smokers. Environ $\mathrm{Mol}$ Mutagen 2002; 40: 168-174.

29 Wei W, Kim Y, Boudreau N. Association of smoking with serum and dietary levels of antioxidants in adults: NHANES III, 1988-1994. Am J Public Health 2001; 91: 258-264.

30 Alberg AJ, Chen JC, Zhao H, Hoffman SC, Comstock GW, Helzlsouer KJ. Household exposure to passive cigarette smoking and serum micronutrient concentrations. Am J Clin Nutr 2000; 72: 1576-1582.

31 Polidori MC, Mecocci P, Stahl W, Sies H. Cigarette smoking cessation increases plasma levels of several antioxidant micronutrients and improves resistance towards oxidative challenge. Br J Nutr 2003; 90: 147-150.

32 Lykkesfeldt J, Christen S, Wallock LM, Chang $\mathrm{HH}$, Jacob RA, Ames BN. Ascorbate is depleted by smoking and repleted by moderate supplementation: a study in male smokers and nonsmokers with matched dietary antioxidant intakes. Am J Clin Nutr 2000; 71: 530-536.
33 Dietrich M, Block G, Norkus EP, et al. Smoking and exposure to environmental tobacco smoke decrease some plasma antioxidants and increase $\gamma$-tocopherol in vivo after adjustment for dietary antioxidant intakes. Am J Clin Nutr 2003; 77: 160-166.

34 Tsuchiya M, Asada A, Kasahara E, Sato EF, Shindo M, Inoue $\mathrm{M}$. Smoking a single cigarette rapidly reduces combined concentrations of nitrate and nitrite and concentrations of antioxidants in plasma. Circulation 2002; 105: 1155-1157.

35 Hulea SA, Olinescu R, Nita S, Crocnan D, Kummerow FA. Cigarette smoking causes biochemical changes in blood that are suggestive of oxidative stress: a case-control study. J Environ Pathol Toxicol Oncol 1995; 14: 173-180.

36 Lam KY, Fu KH, Wong MP, Wang EP. Significant changes in the distribution of histologic types of lung cancer in Hong Kong. Pathology 1993; 25: 103-105.

37 Devesa SS, Shaw GL, Blot WJ. Changing patterns of lung cancer incidence by histologic type. Cancer Epidemiol Biomarkers Prev 1991; 1: 29-34. 